\title{
Evaluation of Efficacy and Safety of Ponatinib as Third-line Treatment in Patients with the Diagnosis of Chronic Phase Chronic Myeloid Leukemia
}

\author{
Pusem PATIR, Nur SOYER, Filiz VURAL, Guray SAYDAM \\ Ege University Faculty of Medicine, Department of Hematology, Izmir, TURKEY
}

Dear Editor,

Philadelphia $(\mathrm{Ph})$ is a fusion protein product of $\mathrm{BCR}$ $\mathrm{ABL}$ and is a structurally active tyrosine kinase that causes chronic myeloid leukemia (CML) and a subgroup of acute lymphoblastic leukemia (ALL). ${ }^{1,2}$ Three tyrosine kinase inhibitors (TKI) (imatinib, dasatinib and nilotinib) targeting the BCR-ABL protein have been approved in the treatment of newly diagnosed chronic phase CML (CML-CP). ${ }^{3-5}$ Ponatinib is an orally applied, third generation strong BCR-ABL inhibitor that demonstrates activity against natural and mutational BCR-ABL proteins. Ponatinib includes a new triple bond connection that prevents the steric barrier that is caused by the remnant of the large isoleucine at 315 th position in the T315I mutation. ${ }^{6}$ Ponatinib has been developed in order to overcome the limitations of TKI that are used in the current management of CML. We hereby retrospectively evaluated 6 patients ( 4 women and 2 men) with the diagnosis of CML and who had loss of response during second-line TKI treatments and who were treated with ponatinib as a third-line treatment.

Median age at the time of launching ponatinib treatment was 58 (46-78) years. Four patients had intermediate risk score and 2 high risk at the time of the diagnosis according to the Sokal risk score. All patients had been treated with imatinib and second generation TKI (3 patients received dasatinib 100 $\mathrm{mg}$ /day and 3 received nilotinib $400 \mathrm{mg} /$ day) prior to the treatment. All patients were screened for mutations and only one patient had T315I mutation. Median duration of switching to ponatinib treatment from second generation TKI treatment was 49 (1873) months. Initial dose of ponatinib was $45 \mathrm{mg} /$ day in 5 patients and $15 \mathrm{mg} /$ day in one patient. The dose was decreased from $45 \mathrm{mg}$ /day to $30 \mathrm{mg} /$ day in 3 patients and from $45 \mathrm{mg}$ /day to $15 \mathrm{mg}$ /day in one patient due to hematological toxicity. The dose was continued as $45 \mathrm{mg} /$ day in one patient with end stage renal failure without any side effects. After a median follow up of 13.5 (3-16) months, optimal response was not achieved in any of the patients subsequent to start of ponatinib treatment based on the European LeukemiaNet $^{7}$ criterion; however, partial cytogenetical response (PCyR) was achieved in 5 patients (Figure 1). Treatment response could not be evaluated in one patient since the patient received the medication irregularly and dropped out of followup. Thrombocytopenia was observed as the main toxicity in ponatinib treatment. Skin rash was seen in one patient. Arterial or venous thromboses were not observed in any of the patients. No death occurred related to the treatment. One patient died during an allogeneic stem cell transplantation from non-sibling HLA-matched donor. No mutations were observed initially or during the treatment. 


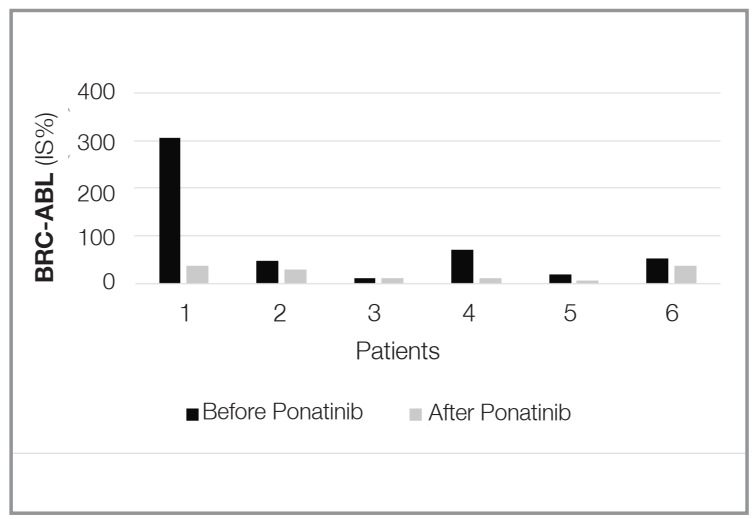

Figure 1. Quantitative $B C R-A B L$ transcript levels after ponatinib in patients

The most important cause of failure of treatment in patients with the diagnosis of $\mathrm{Ph}$ positive CML is resistance to TKI's. Primary and secondary resistance can be detected in about 20-30\% of newly diagnosed CML-CP patients treated with imatinib. ${ }^{3,8}$ Treatment is switched to second generation TKI's, dasatinib or nilotinib in patients developed resistance or intolerance to imatinib and those two drugs may provide complete cytogenetical response (CCyR) in 35-63\% of such patients. ${ }^{9}, 10$ Ponatinib has been demonstrated to be very effective in phase 1 and phase 2 studies including patients with treatment resistance or intolerance regardless of the initially determined mutation status. ${ }^{11,12}$ In a study performed using ponatinib in 43 patients with the diagnosis of $\mathrm{Ph}$ positive CML-CP resistant to two or more TKI's, major cytogenetical response (MCyR), CCyR and major molecular response (MMR) was achieved in $72 \%, 63 \%$ and $44 \%$, respectively. ${ }^{11}$ In that study the most frequent side effects were skin rash, myelosuppression and constitutional symptoms and as dose related side effect, elevation in lipase and amylase levels and pancreatitis. In PACE trial which is a phase 2 study, majority of the 267 patients with the diagnosis of CML-CP and received at least two TKI treatments previously and reached MCyR, CCyR and MMR with ponatinib with the ratio of $56 \%$, $46 \%$ and $34 \%$, respectively. ${ }^{12} \mathrm{~A}$ single center phase 2 clinical trial of ponatinib was designed in 5 patients with CML-CP and resistant or intolerant to only one previous TKI (imatinib, nilotinib or dasatinib). Four patients (80\%) achieved a CCyR at both the 3rd month and 6th month assessment. ${ }^{13}$
In a case series including 10 patients with CML$\mathrm{CP}$ in whom ponatinib was started as second line treatment, 2 patients had no optimal response, while remaining 8 patients had MMR.${ }^{14} \mathrm{CCyR}$ rate was reported as $94 \%$ in the 6th month in a phase 2 study in which ponatinib was used as a first line treatment in patients with the diagnosis of CMLCP. ${ }^{15}$ Although our report includies small number of patients, it could demonstrate that ponatinib treatment might be beneficial in patients with no detectable BCR-ABL mutation such as T315I and with CML-CP and developed resistance to multiTKI treatment. Thrombotic events were not detected in any patients in our cases and this might be due to absence of any underlying comorbid disease that may potentiate development of thrombosis. In addition, absence of cardiovascular events might be explained by decreased drug dosage due to side effects and relatively short term of therapy with full dose of drug.

In conclusion, ponatinib is an important BCR-ABL inhibitor with clinical efficacy in patients with TKI resistant Ph-positive CML with or without mutations. There are some new studies which would clarify the exact dose and regimen of ponatinib in patients with diagnosis of CML and previously treated with first and second generation TKIs. But we can conclude that further studies are required to explore the activity of ponatinib in CML patients not only with mutations but also without any mutations.

\section{REFERENCES}

1. Daley GQ, Van Etten RA, Baltimore D. Induction of chronic myelogenous leukemia in mice by the P210bcr/abl gene of the Philadelphia chromosome. Science 247: 824-830, 1990.

2. Faderl S, Garcia-Manero G, Thomas DA, et al. Philadelphia chromosome-positive acute lymphoblastic leukemia - current concepts and future perspectives. Rev Clin Exp Hematol 6: 142-160, 2002.

3. Druker BJ, Guilhot F, O'Brien SG, et al. Five-year follow-up of patients receiving imatinib for chronic myeloid leukemia. $\mathrm{N}$ Engl J Med 355: 2408-2417, 2006.

4. Kantarjian H, Shah NP, Hochhaus A, et al. Dasatinib versus imatinib in newly diagnosed chronic-phase chronic myeloid leukemia. N Engl J Med 362: 2260-2270, 2010. 
5. Saglio G, Kim DW, Issaragrisil S, et al. Nilotinib versus imatinib for newly diagnosed chronic myeloid leukemia. N Engl J Med 362: 2251-2259, 2010.

6. Zhou T, Commodore L, Huang WS, et al. Structural mechanism of the Pan-BCR-ABL inhibitor ponatinib (AP24534): lessons for overcoming kinase inhibitor resistance. Chem Biol Drug Des 77: 1-11, 2011.

7. Baccarani M, Cortes J, Pane F, et al. Chronic myeloid leukemia: an update of concepts and management recommendations of European LeukemiaNet. J Clin Oncol 27: 6041-6051, 2009.

8. de Lavallade H, Apperley JF, Khorashad JS, et al. Imatinib for newly diagnosed patients with chronic myeloid leukemia: incidence of sustained responses in an intention-to-treat analysis. J Clin Oncol 26: 3358-3363, 2008.

9. Kantarjian H, Giles F, Wunderle L, et al. Nilotinib in imatinibresistant CML and Philadelphia chromosome-positive ALL. N Engl J Med 354: 2542-2551, 2006.

10. Talpaz M, Shah NP, Kantarjian H, et al. Dasatinib in imatinibresistant Philadelphia chromosome-positive leukemias. N Engl J Med 354: 2531-2541, 2006.

11. Cortes JE, Kantarjian H, Shah NP, et al. Ponatinib in refractory Philadelphia chromosome-positive leukemias. N Engl J Med 367: 2075-2088, 2012.

12. Cortes JE, Kim DW, Pinilla-lbarz J, et al. A phase 2 trial of ponatinib in Philadelphia chromosome-positive leukemias. N Engl J Med 369: 1783-1796, 2013.

13. Sanford D, Kantarjian $H$, Skinner $J$, et al. Phase 2 trial of ponatinib in patients with chronic myeloid leukemia resistant to one previous tyrosine kinase inhibitor. Haematologica 100: e494-5, 2015.
14. Breccia M, Abruzzese E, lurlo A, et al. Efficacy and safety of second-line ponatinib after failure of a single previous tyrosine kinase inhibitor for chronic myeloid leukemia patients in chronic phase. Haematologica 101: e267-8, 2016.

15. Jain $P$, Kantarjian $H$, Jabbour $E$, et al. Ponatinib as first-line treatment for patients with chronic myeloid leukaemia in chronic phase: a phase 2 study. Lancet Haematol 2: e37683, 2015.

\section{Correspondence:}

Dr. Pusem PATIR

Ege Üniversitesi Tıp Fakültesi Hastanesi

Hematoloji Anabilim Dalı

35100 Bornova, IZMiR / TURKEY

Telephone: (+90-232) 3903540

Fax: $\quad$ (+90-232) 3903530

e-mail: pusemp@yahoo.com 